\title{
Notes on the vocalizations of Golden-bellied Warbler (Basileuterus chrysogaster)
}

Peter Boesman

In the following we briefly analyze and compare voice of the two races of Golden-bellied Warbler (Basileuterus chrysogaster). We also try to quantify the extent of any vocal differences using the criteria proposed by Tobias et al. (2010), as a support for taxonomic review. We have made use of sound recordings available on-line from Xeno Canto (XC).

Some examples of song, illustrated by sonograms:

chlorophrys

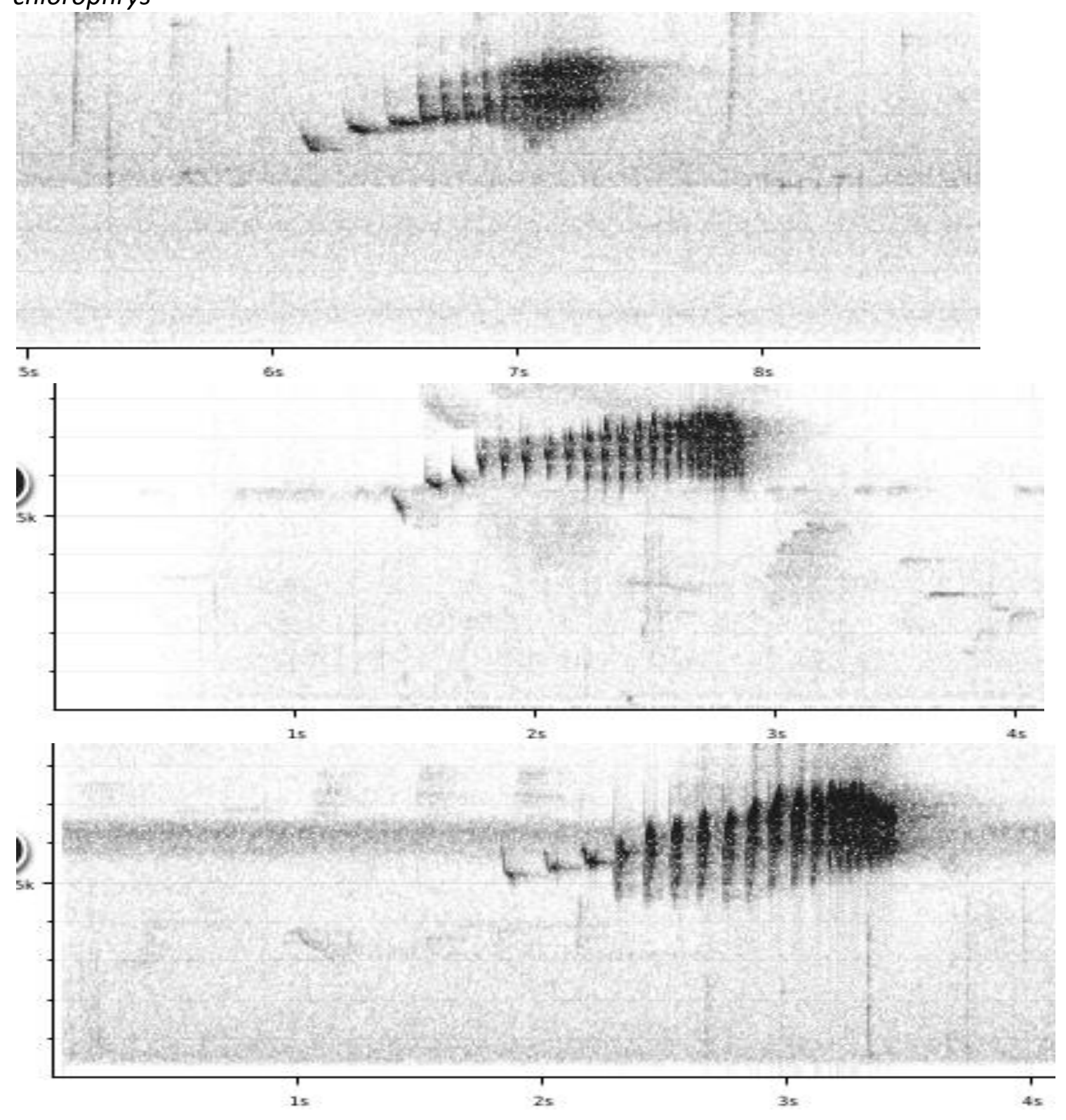


HANDBOOK OF THE

BIRDPFIYUE WORLD ORNITHOLOGICAL NOTES
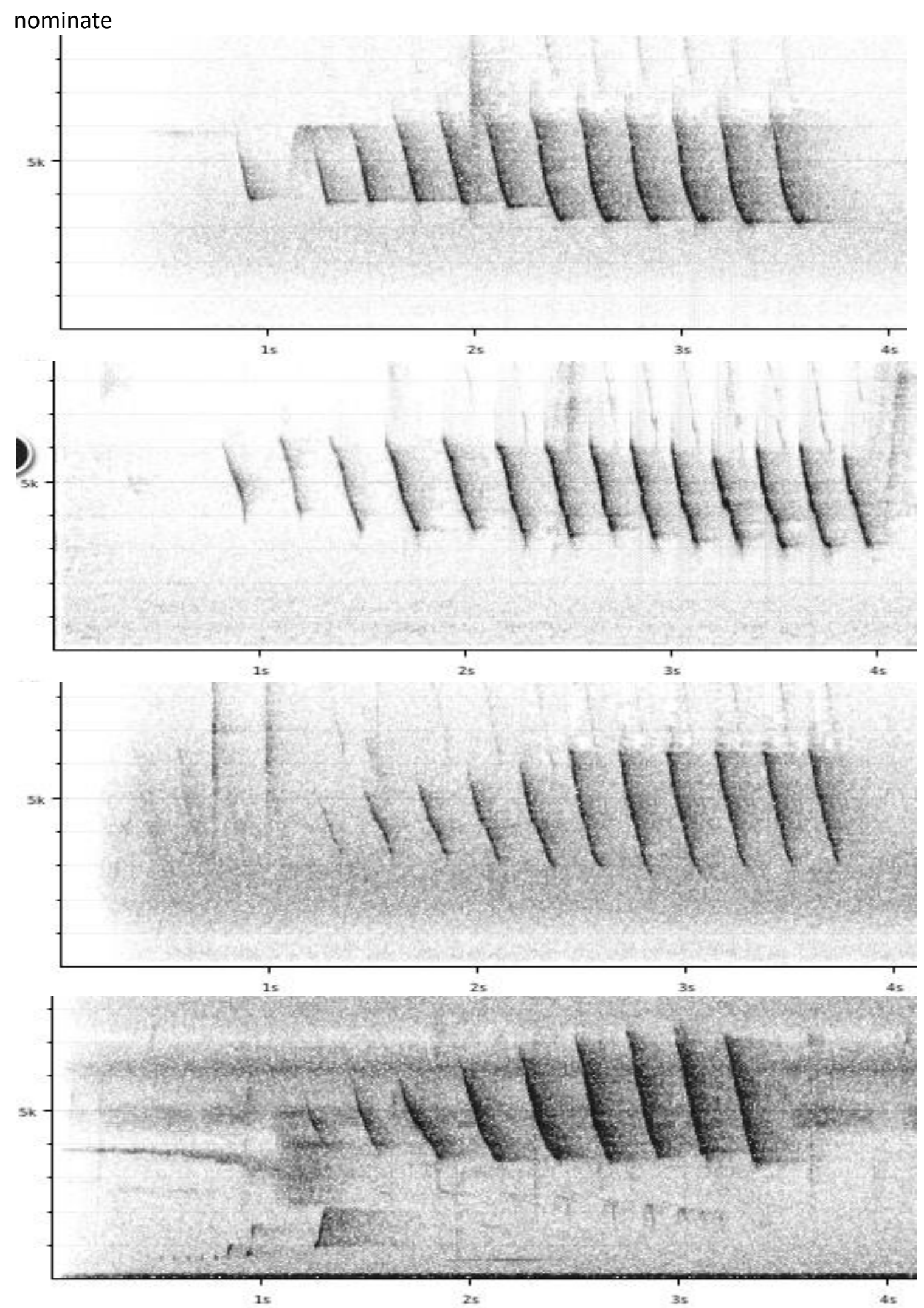

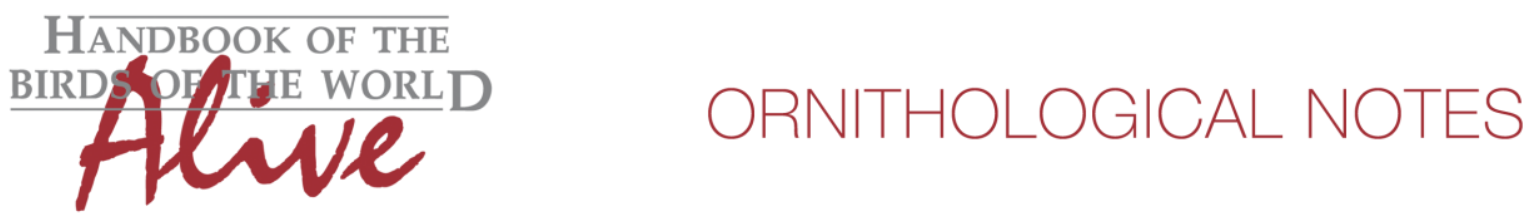

Differences in song are quite obvious:

chlorophrys has a shorter song consisting of many more notes (score 3), which accelerate into a very fast trill with notes hardly countable (high pace, score 3-4), and notes are all at a higher pitch (all notes typically above $5 \mathrm{kHz}$ vs. typically down to $3-4 \mathrm{kHz}$, score 3 ). Aplication of Tobias criteria would lead to a total vocal score of about 6-7.

This note was finalized on 27th June 2016, using sound recordings available on-line at that moment. We would like to thank in particular the sound recordists who placed their recordings for this species on XC: Roger Ahlman, Nick Athanas, Peter Boesman, Tayler Brooks, Diego Calderon, Karolina Fierro-Calderon, Jerome Fischer, Pablo Florez, David Geale, Olaf Jahn, Niels Krabbe, Frank Lambert, Dan Lane, Gabriel Leite, John V Moore, Andrew Spencer and Patricio Meno Valenzuela.

\section{References}

Tobias, J.A., Seddon, N., Spottiswoode, C.N., Pilgrim, J.D., Fishpool, L.D.C. \& Collar, N.J. (2010). Quantitative criteria for species delimitation. Ibis 152(4): 724-746.

\section{Recommended citation}

Boesman, P. (2016). Notes on the vocalizations of Golden-bellied Warbler (Basileuterus chrysogaster). HBW Alive Ornithological Note 377. In: Handbook of the Birds of the World Alive. Lynx Edicions, Barcelona. (retrieved from http://www.hbw.com/node/1252933 on 30 November 2016). 